\title{
The (Identification) Cards You Are Dealt: Biased Treatment of Anglos and Latinos Using Municipal-Issued versus Unofficial ID Cards
}

\author{
Ruth K. Ditlmann \\ Yale University \\ Paul Lagunes \\ Yale University
}

\begin{abstract}
The current field experiment investigated if and how Latinos versus Anglos experience biased treatment in a setting where documentation is relevant. In an audit experiment, Latino customers were treated differently than a matched team of Anglo customers when making $\$ 10$ check payments at retail stores. Specifically, Latinos were asked to present an identification card (ID) more frequently than Anglo customers, were quoted a higher minimum-dollar amount for purchasing a gift certificate, and received more negative affect from salespersons. Among those who were asked for identification, a municipal-issued ID card was declined at equal rates from Latinos and Anglos, while an unofficial ID card was declined more from Anglos than Latinos. The association of Latino identity with foreignness and undocumented immigration, and the potential of municipal-ID card programs to serve undocumented immigrants are discussed.
\end{abstract}

KEY WORDS: Discrimination, Bias, Immigration, Latinos

A report by the Pew Hispanic Center estimated that 11.2 million undocumented immigrants lived in the United States in 2010 (Passel \& Cohn, 2011). Undocumented immigrants living in the United States come from countries all over the world; however, a large majority (76\%) of the nation's undocumented immigrants is Latino. This statistic does not paint an accurate picture of all Latinos residing in the United States, as most are citizens or legal residents (Massey \& Sanchez, 2010). Still, issues of documentation and immigration shape the public image of all Latinos (Castañeda, 2007; Lyman, 2006; Suro, 1998). In light of this public image, the primary objective of the current research is to investigate if and how Latinos versus Anglos experience biased treatment when documentation is relevant. We provide a rigorous design to detect biased behavior and move beyond standard Black/White models of discrimination by situating discrimination in a context where documentation is relevant.

Overwhelming evidence shows that almost all new immigrants are hopeful, law-abiding, familyand community-oriented, and hardworking (Massey \& Sanchez, 2010). Nevertheless, immigrants who are undocumented face hardship while carrying out the most mundane tasks of daily life, such as opening a bank account, securing health insurance, or purchasing goods without cash. From the perspective of American institutions, immigrants' lack of documentation makes it difficult to 
accurately assess the political, economic, educational, and health care needs of the communities they are a part of. Thus, some argue that it is in the best interests of American citizens and undocumented immigrants alike to provide the latter with some form of official or government-sanctioned form of identification.

Against this backdrop, the issue of local municipalities offering official documentation for undocumented immigrants has been of great interest to policy makers and immigration advocacy groups (Lagunes, Levin, \& Ditlmann, 2012; Zapana, 2008). As of this writing, at least five cities in the United States already offer municipal-issued identification cards (IDs) to their residents regardless of ethnicity, citizenship, immigration status, and employment status. Therefore, the second objective of the current research, in addition to testing for biased treatment of Latinos, is to investigate if and how a municipal-issued ID card can serve Latino immigrants in a context where they may otherwise be subject to discrimination by being denied the option of purchasing goods with a check.

We address both objectives, biased treatment of Latinos and the effect of municipal-issued ID cards (i.e., a policy designed to benefit undocumented immigrants) with a field experiment. More specifically, we directly observed salesperson-customer interactions when an ostensible customer attempted to purchase goods with a personal check. By presenting customers whom we matched on age, verbal skill, physical attractiveness, masculinity, and extroversion but who differed by ethnicity (Latino versus Anglo) and legitimacy of identification (municipal-issued versus unofficial), we observed the degree to which considerations about customers' ethnicity and type of identification affected the treatment they received from salespersons (e.g., whether an ID was requested or whether an ID was accepted for check payment).

Furthermore, similar to recent advances in field experimentation (King, Shapiro, Hebl, Singletary, \& Turner, 2006; Pager, Western, \& Bonikowski, 2009; Paluck, 2009), we strive to advance psychological theories of prejudice and discrimination by studying these processes in naturalistic environments. This approach limits us to behavioral (as opposed to affective or cognitive) outcome variables (Cialdini, 2009). However, it uniquely enables us to observe discrimination as it naturally unfolds within social interactions when individuals are unaware of being observed. Studying the multifaceted character of bias in the context of documentation illuminates the range of decisions that may reduce opportunities for people in need of documentation to carry out mundane tasks and that often taint the experience of Latino Americans or documented immigrants who are falsely stereotyped as illegal or undocumented.

\section{The Perpetual Foreigner: Requesting Identification}

American citizens perceive Latinos to be the ethnic minority group most likely to face racial discrimination (Pew Research Center, 2010). This perception maps onto Latinos' self-reported experiences. Young Latinos in their 20s perceive substantial amounts of everyday discrimination (Pérez, Fortuna, \& Alegría, 2008). Archival evidence often implicates discrimination against Latinos; for example, in earnings of Latino-owned firms (Carvajal, 2004) or in capital sentencing (Lee, 2007). Experimental research reveals discrimination against Latinos in simulated jury decision-making contexts (Bottoms, Davies, \& Epstein, 2004) and throughout hiring processes (Cross, Kenney, Mell, \& Zimmerman, 1990; Pager et al., 2009). Finally, research on bias occurring outside of people's awareness reveals that Anglos show bias against Latinos on the Implicit Association Test (Aberson, Shoemaker, \& Tomolillo, 2004; Devos, Gavin, \& Quintana, 2010; Weyant, 2005) and during automatic shooting simulations (Sadler, Correll, Park, \& Judd, 2012).

The present research focuses on a social situation with which Latinos contend on a daily basis: a request for legitimate proof of identification. Our research begins with the assumptions that in the United States, Latinos' legitimacy as legal residents is continuously questioned and that concerns 
about Latinos' legal status shape people's everyday encounters with them. That is, even though the majority of Latinos in the United States are American citizens or legal immigrants, issues of documentation and immigration shape their public image (Abrajano \& Singh, 2009; Castañeda, 2007; Dovidio, Gluszek, John, Ditlmann, \& Lagunes, 2010; Lyman, 2006; Suro, 1998). Indeed, there is a strong association between Latino identity and undocumented immigration. For instance, Americans are most likely to think about Latinos when asked to complete surveys about "illegal aliens" (Cowan, Martinez, \& Mendiola, 1997), and negative rhetoric and ethnic slurs about Latinos in the United States build on people's stereotypes about undocumented immigration (Marshall \& Eberhardt, 2011). Because Latinos are automatically presumed to be undocumented immigrants, people are likely to routinely request proof of identification from them in situations in which documentation is relevant. When purchasing goods in a retail store with a check, for example, salespersons likely ask Latino customers more frequently for identification than Anglo customers, presumably because Latinos invite greater suspicion about their legal status and, thus, the credibility of their checks.

Legally, requests for ID cards do not constitute a form of discrimination. In fact, one may perceive such requests as a racially neutral and wise business practice. Yet, we argue that requesting ID cards at differential rates depending on customers' ethnicity constitutes bias. Moreover, negative affect accompanying requests for ID cards, such as frowns and perceived aggravation, further suggest negative bias. In the context of the current field experiment, our first objective was to examine whether matched pairs of Latino and Anglo customers who attempted to purchase goods with a check were differentially asked for proof of ID and encountered negative affect from salespersons.

\section{Conceptualizing Lack of Documentation: Municipal-Issued or Unofficial Identification}

Our second objective was to examine whether matched pairs of Latino and Anglo customers who attempted to purchase goods with a check could successfully complete the transaction as a function of presenting municipal-issued versus unofficial ID cards. Municipal-issued ID cards are city government-sanctioned personal identification cards available to all residents of participating cities regardless of their immigration status. Unofficial ID cards are non-government-sanctioned personal identification purchased from privately owned companies. Interactions between salespersons and customers are multifaceted. After the customer asks to pay for the purchase with a check, requests for ID cards may be relevant, and the customer must present some form of documentation. The salesperson must then decide whether to reject or accept the documentation in order to complete the sale. In the current experiment, we explored the ongoing processes by which bias against Latinos may occur. After the initial request (or not) for identification, we randomly assigned Latino and Anglo customers to present either a municipal-issued or an unofficial ID card and observed whether salespersons declined or accepted the ID card.

The present research offers a framework for understanding how bias may affect the perceived legitimacy of ID cards. We suggest that in the absence of other information, ID cards convey the credibility of the card owner. Drawing from previous research on ambiguous social contexts and bias (Dovidio \& Gaertner, 2004; Dovidio, Kawakami, \& Gaertner, 2002; Purdie-Vaughns, Steele, Davies, Ditlmann, \& Crosby, 2008), we argue that the degree of ambiguity and legitimacy of the card creates a context in which salespersons will cognitively activate and apply stereotypes, expectations, and assumptions about the person presenting the ID.

We expect salespersons to decline legitimate ID cards at equivalent rates from Latino and Anglo customers. By contrast, we expect illegitimate ID cards to elicit documentation-related stereotypes about Latinos and Anglos. Consequently, we expect salespersons to decline illegitimate ID cards at differential rates depending on customers' ethnicity. 
Two alternative predictions about the direction of this bias are possible. On the one hand, salespersons may be more likely to decline ambiguous ID cards from Latino customers than Anglo customers. Psychological models of stereotyping proposing that individuals engage in bias against minorities when they can attribute their behavior to a given situation support this hypothesis (Crandall \& Eshleman, 2003). An ambiguous ID card offers a situation that provides justification for expressing bias against Latinos.

On the other hand, salespersons may also be less likely to decline an ambiguous card from Latino customers than from Anglo customers. Alternative models of stereotyping propose that perceivers engage in stereotyping when the target's behavior is inconsistent or counterstereotypical (Eagly \& Karau, 2002; Gutiérrez \& Unzueta, 2010). If people typically stereotype Latinos as undocumented immigrants without any documentation, and Anglos as American citizens with documentation, then illegitimate cards may activate a "something is better than nothing" mindset when presented by a Latino and a suspicious mindset ("why would an American have unofficial identification?") when presented by an Anglo. In this case, salespersons are expected to decline the illegitimate card more frequently when presented by Anglos than Latinos.

In the present experiment, we used a "municipal-issued" card as a legitimate ID card. Recently, various cities have experimented with offering municipal-issued forms of identification. These cities offer ID cards to all city residents regardless of their immigration status. Such municipal-issued cards serve as official identification in many situations, for example, checking out a book at the public library, opening a bank account, and making a check payment at local stores. The first municipalissued identification program, the Elm City Resident Card program, started in New Haven, Conn., in 2007. Because it was the first of its kind in the United States, it received substantial public attention and served as a pilot for other cities (Lagunes, Levin, \& Ditlmann, 2012). Since 2007, four cities (San Francisco and Oakland in California; Trenton and Princeton in New Jersey) have adopted similar programs. We used the Elm City Resident Card in our experiment (see Appendix A). Because it has only been introduced in the last five years, the Elm City Resident Card may not be as familiar to institutions in the municipalities as federal-issued ID cards (e.g., passports, driver's licenses). From the perspective of stores, however, municipal-issued cards should be credible because the source that certifies the information on the card-the city government-is trustworthy.

Secondly, we used an unofficial card as an illegitimate ID card (see Appendix A). We use the term "unofficial identification" to describe non-government-sanctioned personal identification purchased from privately owned companies. To obtain much needed documentation, individuals often purchase unofficial ID cards in vending locations around the country in the hope that local institutions will accept them. In contrast to municipal-issued cards, these cards are not sanctioned by any government institution, and very few requirements exist for purchasing them. From the perspective of stores, unofficial cards are less credible because the source that certifies the information on the card - a private company that makes money by selling ID cards-is unknown and untrustworthy.

\section{The Current Experiment}

Past research clearly establishes that bias against Latinos exists (e.g., Aberson et al., 2004; Bottoms, Davis, \& Epstein, 2004; Devos et al., 2010; Sadler et al., 2012). However, because prior studies have primarily been conducted in the laboratory, they fail to identify real social contexts in which Latinos actually experience discrimination, as well as the nature and extent of discrimination against Latinos. Laboratory experiments of discrimination infer salespersons' behavior from data obtained using basic paradigms and college-student samples. Moreover, surprisingly few empirical studies in psychology actually focus on discriminatory behaviors and instead focus on attitudes and beliefs that are assumed to predict discrimination (Paluck \& Green, 2009). The present research diverges from common practice. We used a field experiment to test whether biased behavior exists 
in retail stores, a real-world setting with which most Americans engage frequently. Furthermore, we tested the effectiveness of a real and current policy, municipal ID cards, for combating negative treatment of Latinos. The current approach, referred to as an audit methodology, involved the use of matched teams of customers - testers-who attempted to purchase real goods with a check and recorded a variety of responses about the course of the interaction with the salesperson. Because our Latino and Anglo testers were matched on a wide variety of characteristics (e.g., age, masculinity) and dressed uniformly, confounds that provide alternative explanations to bias (e.g., social class and idiosyncrasies of individual testers and social class) were controlled. In part due to logistical requirements, in-person audit studies are rare, with only a handful of existing studies on discrimination against Latinos (Kenney \& Wissoker, 1994; Marianne, 1995; Ondrich, Stricker, \& Yinger, 1999; Pager et al., 2009). To our knowledge, our study is the first to examine both ethnicity and type of documentation in the same experiment. In addition, we extended our analysis beyond card decline and acceptance rates to examine a richer set of outcomes that capture emotional reactions in the salesperson-customer interaction. By using a comprehensive set of outcomes in a field setting, we provide a unique window into how bias unfolds over the course of an interaction and the nature of the bias that Latinos may face on a daily basis.

We hypothesized that matched pairs of Latino and Anglo testers who attempted to purchase goods with a check would be asked for proof of identification at different rates and would encounter different rates of negative affect from the salesperson. In addition, we expected no difference in the rate at which salespersons would decline the municipal-issued card from Latino and Anglo customers. By contrast, the unofficial card was expected to lead salespersons to engage in bias. Specifically, we tested whether salespersons would be more or less likely to decline an unofficial ID card from Latino customers than from Anglo customers.

\section{Method}

In our field experiment, we randomly assigned Latino and Anglo testers to make check payments for $\$ 10$ gift certificates in retail stores and compared how salespersons responded to this request. Hindering Latinos from making small purchases with a check excludes them from a basic, everyday activity in which their immigration status is irrelevant. To maximize standardization across stores, we instructed testers to purchase gift certificates instead of products. Many stores have a $\$ 10$ (or less) minimum for gift certificates. To ensure that all purchases had a chance of being successful (while keeping the overall cost for the experiment reasonably low), testers attempted to make $\$ 10$ giftcertificate purchases. If a salesperson asked for ID, we randomly assigned testers to present the municipal-issued versus unofficial card. We assessed several objective outcomes (e.g., ID-card request) and one subjective outcome (facial expression) to capture biased treatment in the store.

\section{Participants}

We recorded the responses of salespersons towards testers in a total of 217 stores in downtown New Haven, Conn., and in three nearby malls. As a result of random assignment, Latino testers visited 111 stores, and Anglo testers visited 106 stores. Testers were also randomly assigned to present the municipal card in 97 stores and the unofficial card in 118. However, they only presented it if the salesperson asked for it, an issue we address and discuss in the results section and in Appendix B.

\section{Procedure}

We sent three matched pairs of Latinos and Anglos to purchase \$10 gift certificates using check payment in 217 stores. The testers were young men, aged 24 to 30. Most were between 5'9 and 6' 1 
in height, and all were recruited in New Haven, Conn. We provide more detail on how they were selected and matched below. In each store, testers presented either the municipal-issued card or the unofficial card, if asked. The municipal-issued Elm City Resident Card presents the holder's personal information. It is clearly labeled "Elm City Resident Card" in large print and "New Haven Municipal Identification Card" in small print on the front. Like the Elm City Resident Card, the unofficial ID card contains the holder's personal information but is also labeled with the brand name "Ameracard" and "Connecticut" in bold on the front. An inscription on the back states: "Not an official identification card" (See Appendix A).

Throughout a period of four weeks, we randomly assigned 7-10 stores on a given day from our sample of 217 stores to Latino versus Anglo testers. At the beginning of each day, we provided them with the list of stores they were randomly assigned to for this day. Before testers entered a store, they drew one of the two ID cards, municipal-issued or unofficial, from a shuffling bag so as to randomly assign themselves to one of the ID-card conditions while remaining unaware of the type of ID they were going to present (i.e., testers selected a card and put it in their pocket without looking at it).

Following the same script, testers individually entered each store and asked to purchase a $\$ 10$ gift certificate. If the salesperson responded that the minimum for gift certificates was higher than $\$ 10$ (typically $\$ 15$ ), they accepted that higher minimum. Each store was visited only once. When prompted for payment, the testers asked whether the store accepted checks. When salespersons asked them to present ID, the testers presented the card they had drawn before entering the store. If the card was accepted, they completed the purchase transaction. One of the challenges of studying the nature of bias as it unfolds in ongoing, real-world interactions is selective attrition. In our study, only testers who were asked to present ID had an opportunity to observe whether that ID card was declined. We address this threat to internal validity analytically in Appendix C. Fortunately, the random assignment of card to store is uncompromised within Latino and Anglo targets.

After leaving the store, testers immediately filled out a report sheet that included information on the store and our outcome variables. Specifically, they recorded (1) whether the salesperson asked them for ID, (2) what minimum price they were quoted for the gift certificate, (3) the salesperson's facial expressions during the initial attempt to purchase the goods (i.e., smile, neutral expression, frown), and (4) whether the ID card they presented was declined. For the coding of salespersons' facial expressions, testers applied what was learned during several extensive training sessions and coded salespersons' facial expression at the moment of receiving the ID as a smile, neutral expression, or frown. For example, following Ekman and Friesen (1976), they counted a frown as any facial gesture that involved a lowering of the brows and a vertical wrinkling of the forehead area between the eyes. Similarly, they counted a smile as any facial gesture that involved widening of the eyes and pulling up of the lip corners or actual showing of teeth.

To rule out several alternatives to testers' ethnicity that might account for our findings, we coded the types of stores in 13 categories based on the primary products they sold (e.g., apparel, jewelry, home) and recorded testers' perceptions of salespersons' ethnicities in five categories (Anglo, Black, Latino, Asian, Other/Don't Know).

Tester matching and preparation. One frequent criticism of audit studies is that race/ethnicity is difficult, if not impossible, to manipulate in naturalistic environments and that it is therefore difficult to pinpoint the causal effect of this variable. Idiosyncrasies of testers may drive the observed effects (Heckman, 1998). Most of this criticism is directed primarily towards hiring studies, which constitute the core of audit studies. Customer-cashier interactions are far less complex and more structured than employer-prospective employee interactions, making it easier to achieve a high level of standardization across different individuals. Nevertheless, we took several measures to assure maximal comparability between testers in both groups.

We carefully chose our testers to match on several important dimensions (age, verbal skills, physical attractiveness, masculinity, and extroversion). Heavy recruiting efforts resulted in over 40 
in-person interviews of individuals who fulfilled the strict residency requirements necessary to obtain the municipal-issued ID card. The first author and a research assistant conducted the interviews with potential testers. We independently rated applicants on verbal skills, physical attractiveness, masculinity, and extroversion on a 7-point scale following each interview. As a next step, the two authors examined and discussed the ratings.

We chose three Latino and three Anglo testers who looked typical for their ethnicity. In a pilot test, we asked 16 undergraduates to guess for each tester whether he was "Latino" or "White" based on viewing photographs. To preserve our testers' anonymity, we blocked the eye section in these photographs. Of the 96 guesses by 16 undergraduates who each viewed all six testers, $73 \%$ were correct. Only 5\% of the guesses were incorrect, and the rest were "I don't know" guesses. Furthermore, the undergraduates rated our three Latino testers as more "Latino" ( $M=4.8, S E=.25$ versus $M=1.85, S E=.25 ; t(15)=7.40, p<.01)$ and less "White" looking $(M=2.89, S E=.29$ versus $M=6.02, S E=.26 ; t(15)=6.63, p<.01)$ than our three Anglo testers on a 7-point scale. Under conditions that are deprived of several important ethnicity cues available to salespersons in stores (e.g., mannerism, accent, name), $73 \%$ correct guesses give us confidence that the ethnicity of our testers was easy to identify for salespersons in stores.

We also ensured that our Latino testers had names of Hispanic origin, while our Anglo testers had names of British origin. This is important because the ID cards they presented in the stores displayed our testers' real names. Two of our Latino and one of our Anglo testers had a foreign accent (Hispanic and British).

Once we had selected six testers, we prepared them with a nine-day extensive training session that involved memorizing and practicing the script through role-playing in the laboratory; standardizing testers' appearances, verbal, and nonverbal behaviors; and learning and practicing assessment of salespersons' facial expressions. The assessment of facial expressions included a presentation by an expert on nonverbal communication, a discussion of photographs with different facial expressions that focused on objective criteria for differentiating between smiles, neutral expressions, and frowns (e.g., a vertical wrinkling of the forehead), and role-playing with other testers from the same ethnic background. Testers learned to identify one moment in the interaction when they were to "take a mental snapshot" of the salesperson's facial expression to maximize objectivity. They were instructed to tap their left foot at the exact moment when they "took the picture." This tap solidified the snapshot method and allowed an external observer to examine whether testers were applying what they had learned during the training session in the experimental phase. At the end of the training session, we conducted separate trials with each tester in actual stores. During these trials, we validated the assessments of the tester and continued training if the tester's assessments deviated from our own assessments of the salesperson or if the tester's behavior deviated from the script or the behavior of other testers. For example, one tester spoke quietly. We continued to practice with him until his voice was comparable to that of the other testers.

To ensure that differences in awareness and expectation of ethnicity-based rejection were not confounded with the ethnicity of testers, we kept them unaware of our discrimination hypothesis by separating the Latino from the Anglo testers throughout the entire study. In addition, we emphasized our interest in comparing the municipal-issued ID card to the unofficial ID card to distract them from thinking about their ethnicity. In a final evaluation, we asked our testers what "the study was about." Only one Anglo and one Latino tester stated clearly that testing for ethnic discrimination was one of the objectives. We checked if their responses deviated systematically from the rest of their group and combined them with the rest of the group after confirming that this was not the case.

Of the 217 tester interactions in the stores, 34 were monitored by a trained observer who was blind to the study predictions. The observer recorded whether the testers deviated from the script (yes or no) and rated their nonverbal behaviors on two 1-7 scales (not at all to extremely): "How neutral was the tester in the interaction with the salesperson?" and "How friendly was the tester in the 


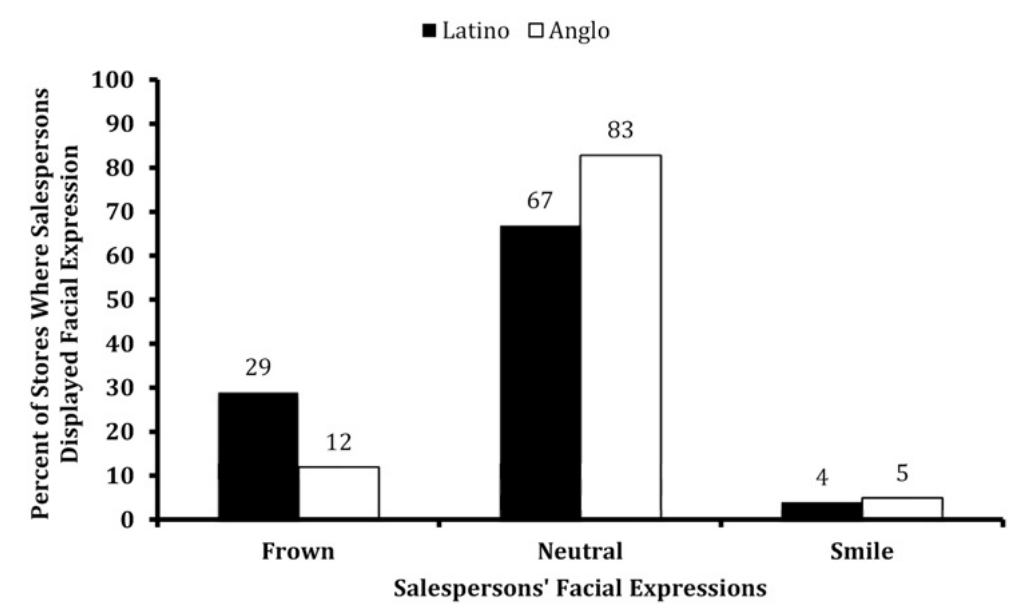

Figure 1. Nonverbal responses of salespersons to Latino and Anglo testers.

interaction with the salesperson?" These two items, with the first one reverse scored, were combined to form a single index of "friendliness" (Cronbach's $\alpha=.73$ ). The observer did not detect a single deviation from the script and detected no significant difference in Latino and Anglo testers' friendliness, $t(32)=1.12, p=.27$. Together with our careful matching procedure and extensive training, the secret-observer results give us confidence that the between-groups effects we observed are due to ethnicity rather than idiosyncrasies of individual testers.

\section{Results}

\section{Requesting ID Cards}

Accent did not interact with ethnicity to predict any of our outcomes and was thus not included in the analyses reported here. If individuals think of Latinos as perpetual foreigners, potentially with undocumented presence in the United States, then salespersons should be more likely to request identification from Latino testers than Anglo testers. Furthermore, salespersons should display more negative affect towards Latino testers as an indication of annoyance or displeasure at having to serve them. For the same reason, they may also quote a higher minimum-dollar amount for the gift certificate. ${ }^{1}$ Consistent with this reasoning, we found that salespersons asked Latino testers for identification more frequently than they asked Anglo testers for identification (85\% versus $74 \%$, $B=.68, S E=.34, p=.05$; see Appendix B for a detailed listing of the findings for each tester). Next, multinomial regression was used to test the effect of tester ethnicity on salespersons' facial expressions. We excluded 45 stores where salespersons did not request identification because facial expression assessments were made when the card was handed to the salesperson. We found that, together with asking for ID more frequently, salespersons expressed a higher ratio of frowns relative to neutral expressions when serving Latino testers compared to Anglo testers $(B=1.14, S E=.42$, $p<.01$; see Figure 1). ${ }^{2}$ There was no effect of ethnicity on the ratio of smiles relative to neutral expressions $(B=.08, S E=.73, p=.91)$.

\footnotetext{
${ }^{1}$ One aspect of these data was presented as part of a larger essay on Latinos in the United States (Dovidio et al., 2010).

${ }^{2}$ Close inspection of this finding shows that it is largely driven by one of our Latino testers ("Latino 2"). If we remove responses to him from the analyses, the effect is no longer significant. However, descriptively, Latino testers still received more frowns (14\% of stores) than Anglo testers (11\% of stores).
} 
In addition, Latino testers were more likely to be quoted a higher minimum-dollar amount for the gift certificate than Anglo testers. Logistic regression was used to test the effect of tester ethnicity on the minimum-dollar amount ( $\$ 10.00$ was coded as 0 , more than $\$ 10.00$ was coded as 1 ). Though both Latino and Anglo testers asked to buy $\$ 10$ gift certificates in the stores they visited according to random assignment, we found that salespersons who interacted with Latinos were more likely to claim that the store's minimum-dollar amount for a gift certificate was greater than $\$ 10$ (9\% for Latinos versus $2 \%$ for Anglos, $B=1.64, S E=.78, p=.04$ ). A Mann-Whitney test confirms these findings by showing that the mean rank for minimum-dollar amount is significantly higher for Latino testers, 113, than for Anglo testers, 105, $U=5455, p=.02$, two-tailed. ${ }^{3}$ Including store type, salesperson gender, salesperson ethnicity, and minimum-dollar amount in the analyses did not change any of the relevant significance levels.

To rule out the alternative explanation that differences in minimum-dollar amount were due to particular store characteristics versus the ethnicity of the testers, we called all stores visited by Latinos after the conclusion of our experiment and asked whether they had a minimum-dollar amount for purchasing gift certificates. All but one of the stores that quoted a minimum amount higher than $\$ 10$ to our Latino testers claimed on the phone several months later that they sell gift certificates for $\$ 10$ or less.

Taken together, our results suggest that Latinos experience biased treatment in the retail context. When attempting to purchase goods with a check, Latino testers are more likely than Anglo testers to be asked for identification, frowned at by the salesperson during this request, and quoted a higher minimum price for purchasing a gift certificate.

\section{Declining ID Cards}

We expected that salespersons would decline the legitimate municipal-issued card at equivalent rates from Latino and Anglo customers. By contrast, the illegitimate unofficial card was expected to elicit stereotypes about Latinos and Anglos relevant to documentation and lead salespersons to engage in bias.

To test for a tester's ethnicity (Latino, Anglo) x ID type (municipal-issued card, unofficial card) interaction, we analyzed the effect of ethnicity, identification type, and the interaction of ethnicity $x$ identification type on whether tester's ID card was declined or accepted in logistic regression. No overall difference emerged on how often salespersons refused IDs from Latino testers compared to from Anglo testers $(B=-.58, S E=.54, p=.28)$. However, a main effect of ID type $(B=-1.26$, $S E=.52, p=.02)$ that was qualified by a significant ethnicity $\times$ ID type interaction emerged $(B=1.61, S E=.70, p=.02$; see Figure 2$)$.

The difference in the percentage times the municipal-issued ID card was refused from Latino $(32 \%)$ versus Anglo $(21 \%)$ testers was not statistically significant $\left(\chi^{2}(1, N=75)=1.18, p=.28\right)$. Thus there was no reliable difference in the rate at which salespersons declined the municipal-issued card from Latino and Anglo customers. Interestingly, salespersons declined a municipal-issued identification card in $27 \%$ of the stores in which it was presented, an issue we will return to in the discussion. Salespersons' refusal of the unofficial card did vary depending on the tester's ethnicity. The Latino testers' unofficial card was refused far less (24\%) than the Anglo testers' unofficial card (48\%), $\chi^{2}(1, N=97)=5.68, p=.02$, suggesting that salespersons favored Latino over Anglo testers in this instance.

\footnotetext{
${ }^{3}$ Close inspection of this finding shows that it is driven by one of our Latino testers ("Latino 3"). If we remove responses to him from the analyses, the effect is no longer significant. Interestingly, in our pilot study, 16 undergraduates rated Latino 3 as looking significantly more "Latino" $(M=5.69, S E=.28)$ than Latino 1 and Latino $2(M=4.47, S E=.32) t(15)=-2.98$, $p<.01$.
} 


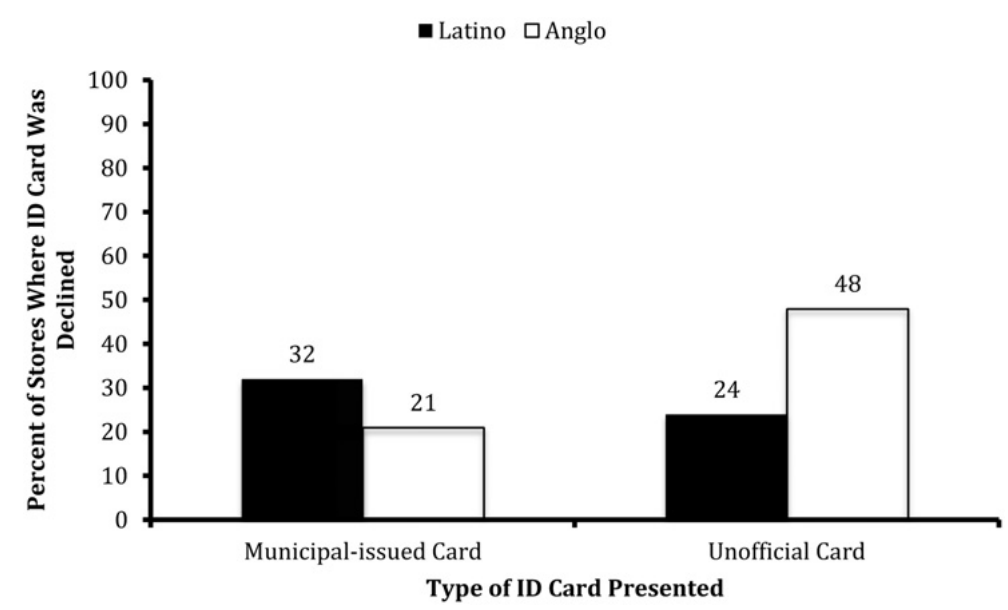

Figure 2. Decline of ID card by testers ethnicity and type of ID card.

This general conclusion holds if we assume different plausible outcomes for the salespersons that dropped out of the study before the ID decline outcome because they did not request ID from the testers to begin with (see Appendix C). Overall, salespersons declined the unofficial ID card in $36 \%$ of the stores, significantly more than the municipal ID card $(B=-1.26, S E=.52, p=.02)$. Including store-type, salesperson gender, salesperson ethnicity, and minimum-dollar amount in this analysis did not change any of the relevant significance levels. Accent did not interact with ethnicity and type of ID to predict ID decline and was thus not included in the analyses reported here. Taken together, our findings show that salespersons decline the municipal-issued card at equivalent rates from Latino and Anglo customers. By contrast, the unofficial card leads salespersons to engage in bias. Specifically, salespersons were less likely to decline an unofficial ID card from Latino customers than from Anglo customers.

\section{Supplementary Analyses}

The municipal ID card is legitimate because the source that certifies the information on the card - the city government-is trustworthy. However, salespersons may be unfamiliar with the municipal-ID card program and thus are unsure how to handle the card in the store. ${ }^{4}$

To explore whether salespersons were aware of the municipal ID-card program, we conducted two sets of supplementary analyses. First, we compared the rates of card decline in downtown New Haven versus surrounding shopping malls. Logistic regression was used to test the effect of tester ethnicity and location on ID-card decline, restricting the sample to stores where the municipal-issued ID card was presented. However, no significant main effect or interaction emerged, all $p s>.10$. This suggests that salespersons downtown were not aware of the municipal-issued ID-card program at different rates from salespersons in shopping malls, despite their geographical proximity to the city government and its public campaign efforts.

Second, we observed and analyzed how often salespersons asked for an explanation of the presented ID card. A chi-square test revealed that salespersons were more likely to ask for an explanation if the municipal-issued ID card (20\% of stores) versus the unofficial ID card (9\% of stores) was presented, $\chi^{2}(1, N=170)=4.36, p=.04,2$ missing. This suggests that salespersons were not aware of the municipal-issued ID-card program. Thus, they probably did not decline the card

\footnotetext{
${ }^{4}$ Because legitimacy of the municipal-issued ID card is a key characteristic, designs of municipal-issued ID cards should ideally reflect their legitimate nature (Lagunes et al., 2012).
} 
because they disagreed with the policy or because they presumed all cardholders to be undocumented but rather because they were unsure how to handle the card in the store.

\section{Discussion}

In line with our predictions, Latino customers who attempted to purchase goods with a check were asked for proof of documentation more frequently than matched Anglo customers, and they encountered more negative affect from salespersons. The difference in probability of being asked for ID between Latino customers (probability of being asked for ID: .85) and Anglo customers (probability of being asked for ID: .74) was of relatively small magnitude. However, shopping is clearly an important everyday activity - based on nationwide statistics, 55\% of Americans have shopped at least once in the past week (MORI Research \& Newspaper Association of America, 2009). Therefore, even if the bias we observed is somewhat small, it likely accumulates over many commercial interactions. It may be perceived by Latinos as a subtle everyday hassle and, over time, cause substantial harm to targets (Sue et al., 2007).

It is also the case that Latinos likely experience differential treatment of much greater magnitude when immigration status is directly relevant, as when Latinos are stopped by authorities in Arizona under the new and controversial Senate Bill 1070. This Bill requires police officers to stop individuals and check for their immigration status, if they have "reasonable suspicion" about the legality of their presence in the United States (State of Arizona House of Representatives 2010, 3-4). Our results show that merely appearing Latino can create suspicion about whether one holds proper documentation.

As predicted, there was no reliable difference in how often salespersons declined the municipal-issued card from Latino versus Anglo testers. Salespersons declined the unofficial card more frequently from Anglo than from Latino testers. This implies that Latinos received the same rate of decline when presenting the municipal versus unofficial ID card. Anglos, in contrast, experienced higher rates of decline with the unofficial than with the municipal ID card. This direction of bias is predicted by psychological models of stereotypical expectations (Eagly \& Karau, 2002; Gutiérrez \& Unzueta, 2010). Consistent with previous research on Latinos as perpetual foreigners (Cowan et al., 1997; Marshall \& Eberhardt, 2011), expectations about official documentation from Latinos appear to be low as Latinos are more likely to be seen as undocumented than Anglos. Their low expectations for Latinos presumably led salespersons to accommodate Latinos who presented an unofficial ID. Conversely, their high expectations for Whites led them to obstruct Whites who presented an unofficial ID. Perhaps the unofficial card introduces a "something is better than nothing" mindset for Latinos and a suspicious mindset for Anglos ("why would an American have an unofficial ID?"). At the moment, we lack clear evidence for these mindsets. However, anecdotally, we found that the only time a salesperson became suspicious and called security was when an Anglo tester presented the unofficial card. We also observed that, when stores made phone calls to authenticate the unofficial card, Latinos were more frequently given the benefit of the doubt than Anglos.

An alternative explanation for why salespersons declined the unofficial card more frequently from Anglo than from Latino testers is that they were afraid to violate egalitarian norms and provide bad customer service. The quality of customer service significantly predicts customers' satisfaction with the product and company, customers' loyalty, and customers' repeat business (King et al., 2006). In such an environment where social norms are so clearly egalitarian, concerns about appearing prejudiced sometimes lead Anglos to overcorrect for their prejudice and treat minorities better than Anglos (Allen, 1975; Crandall \& Eshleman, 2003; Dutton, 1971; Pearson, Dovidio, \& Gaertner, 2009). For example, Dutton (1971) found that restaurant attendants were more likely to allow Black than Anglo customers to violate a formal-attire code. Similarly, salespersons may have declined the 
unofficial card less frequently from Latinos than Anglos in the current experiment to maintain a nonprejudiced appearance and self-concept.

Both the shifting stereotypes and the norm-violation model presume that the cause of the biased treatment we observe is based on Latinos' supposed foreignness combined with lack of documentation. Instead, salespersons may treat Latinos and Anglos differentially because they associate Latinos with low economic status or high criminal intent (Ramirez Berg, 2002). However, to counteract the effect of stereotypes about social class, testers wore standardized clothing typical of middle-class customers. Furthermore, to minimize salespersons' potential fear of crime, the financial stakes were kept low-testers made or attempted to make a low-risk purchase of $\$ 10$.

More importantly, while the socioeconomic and criminal stereotypes explain why salespersons would request to see an ID card more frequently from Latino than Anglo customers, the stereotype of being undocumented is the only one that also explains salespersons' lower propensity to decline the unofficial card from Latino customers. Expectations with regards to low economic status or criminal intent should, if anything, lead salespersons to decline an unofficial card.

As is common in field experiments (Cialdini, 2009), we lack the evidence to arrive at a strong conclusion about the psychological mechanisms at play. Salespersons may decline the unofficial card at higher rates from Anglos than Latinos because of shifting standards that presume Latinos to be foreign and undocumented or because they worry about violating egalitarian norms. However, by showing how the same stereotype can manifest in discrimination and preferential treatment toward Latinos throughout the course of an interaction, our study underscores the importance of testing theories of discrimination in the field (Gerber \& Green, 2012).

In the current experiment, the municipal-issued ID card failed to provide an advantage over and above an unofficial ID card for Latino customers attempting to make a check payment. The experiment was conducted within the conditions that are known to facilitate reliance on shifting standards and social norms. Based on prior research (Biernat \& Kobrynowicz, 1997; Biernat, Kobrynowicz, \& Weber, 2003; Crandall \& Eshleman, 2003; Kahneman, 2011), salespersons may be especially likely to rely on shifting standards and social norms when making quick, minimal-cost decisions that are of little personal consequence. Future research could randomize whether salespersons make rapid versus more analytical decisions (e.g., by asking them to explain their decision), the cost of the item that testers purchase with their check, and whether store managers hold salespersons accountable for their decisions. Perhaps the municipal ID-card program will unfold benefits for Latinos under such different circumstances.

The type of ID card people of different ethnicities present can have additional effects beyond what we consider in the present research under naturalistic conditions. For example, it is possible that the confidence that comes from knowing that one holds a legitimate ID card can lead to greater acceptance of the municipal-issued ID card. Salespersons may be less likely to question the validity of an ID card that is presented confidently (Vrij, 1993). We note, however, that to control for such an influence in the current experiment, we employed a shuffling procedure that effectively kept testers unaware of the card they presented to the salesperson. Nevertheless, future research might productively consider testing if carrying a municipal ID card and being aware of that fact instills a confidence in Latino customers that leads to lower rates of card decline.

Our supplementary analysis section suggests that the relatively high rate of decline of the municipal ID card overall may be attributed to salespersons' lack of awareness of the municipal ID-card program. Even though the card is clearly issued by the city of New Haven, many salespersons seemed unsure about whether accepting the card as a valid form of identification for check payment was consistent with their store's policies. Future research might randomly assign some stores to receive information about the municipal ID-card program in the mail. To the extent that salespersons did not fully understand the policy, the municipal ID card may be accepted at a higher 
rate overall in stores that receive information in the mail and thus better serve Latinos as well as Whites than the unofficial ID card.

Finally, it is important to note that even though the municipal-issued ID card does not provide a benefit for Latinos in terms of its rate of decline in the present research, it has several practical advantages. It allows individuals to open an account in a number of banks, which is an important precondition for safeguarding money and writing checks. Furthermore, it is cheaper than the unofficial ID card ( $\$ 40$ versus $\$ 10$ ) and, because of stringent requirements, is much more difficult to obtain under false premises. The previous point in particular is an advantage not only for individuals using the card but also for municipalities issuing this type of card.

\section{Conclusion}

By examining the interactions between salespersons and customers, this article presents new insights into how ethnicity and identification type influence salespersons' perceptions of the customer's legitimacy. Studying the multifaceted character of bias in the context of documentation illuminates how strongly Latino identity is linked with behavioral indicators of stereotypes about lack of documentation and perpetual foreignness. Overall, our findings build on previous research that demonstrates that even though the majority of Latinos are American citizens and legal immigrants, issues of documentation and immigration shape their public image (Castañeda, 2007; Lyman, 2006; Suro, 1998). They also demonstrate the complexities surrounding policies that benefit the 11.3 million undocumented immigrants in the United States who are, in fact, undocumented and therefore in need of documentation to carry out everyday activities. More research of the kind presented in this article is critical for understanding what, if anything, these programs have to offer to both documented and undocumented Latinos and how such benefits unfold.

\section{ACKNOWLEDGMENTS}

We gratefully acknowledge the helpful comments of John Dovidio, Donald Green, and Valerie Purdie-Vaughns on previous versions of this article. This research was supported by the Yale Institution for Social and Policy Studies. Correspondence concerning this article should be sent to Ruth Ditlmann, Social Science Research Center Berlin, Migration and Diversity Unit, Reichpietschufer 50,10785 Berlin, Germany. Email: ditlmann@wzb.eu

\section{REFERENCES}

Aberson, C. L., Shoemaker, C., \& Tomolillo, C. (2004). Implicit bias and contact: The role of interethnic friendships. Journal of Social Psychology, 144(3), 335-347. doi:10.3200/SOCP.144.3.335-347

Abrajano, M., \& Singh, S. (2009). Examining the link between issue attitudes and news source: The case of Latinos and immigration reform. Political Behavior, 31(1), 1-30. doi:10.1007/s11109-008-9067-8

Allen, B. P. (1975). Social distance and admiration reactions of "unprejudiced" Whites. Journal of Personality, 43(4), 709-726. doi:10.1111/j.1467-6494.1975.tb00731.x

Biernat, M., \& Kobrynowicz, D. (1997). Gender- and race-based standards of competence: Lower minimum standards but higher ability standards for devalued groups. Journal of Personality and Social Psychology, 72(3), 544-557. doi:10.1037/0022-3514.72.3.544

Biernat, M., Kobrynowicz, D., \& Weber, D. L. (2003). Stereotypes and shifting standards: Some paradoxical effects of cognitive load. Journal of Applied Social Psychology, 33(10), 2060-2079. doi:10.1111/j.1559-1816.2003.tb01875.x

Bottoms, B. L., Davis, S., \& Epstein, M. E. (2004). Race and jurors' decisions in child sexual abuse cases. Journal of Applied Social Psychology, 34(1), 1-33.

Carvajal, M. J. (2004). Measuring economic discrimination of Hispanic-owned architecture and engineering firms in south Florida. Hispanic Journal of Behavioral Sciences, 26(1), 79-101. doi:10.1177/0739986303261914

Castañeda, J. G. (2007). Ex mex: From migrants to immigrants. New York: The New Press. 
Cialdini, B. R. (2009). We have to break up. Perspectives on Psychological Science, 4(1), 5-6. doi:10.1111/j.17456924.2009.01091.x

Cowan, G., Martinez, L., \& Mendiola, S. (1997). Predictors of attitudes toward illegal Latino immigrants. Hispanic Journal of Behavioral Sciences, 19(4), 403-415. doi:10.1177/07399863970194001

Crandall, C. S., \& Eshleman, A. (2003). A justification-suppression model of the expression and experience of prejudice. Psychological Bulletin, 129(3), 414-446. doi:10.1037/0033-2909.129.3.414

Cross, H., Kenney, G., Mell, J., \& Zimmerman, W. (1990). Employer hiring practices: Differential treatment of Hispanic and Anglo job applicants. Washington, DC: Urban Institute Press.

Devos, T., Gavin, K., \& Quintana, F. J. (2010). Say “Adios" to the American dream? The interplay between ethnic and national identity among Latino and Caucasian Americans. Cultural Diversity and Ethnic Minority Psychology, 16(1), 37-49.

Dovidio, J. F., \& Gaertner, S. L. (2004). Aversive racism. In M. P. Zanna, \& M. P. Zanna (Eds.), Advances in experimental social psychology (vol. 36, pp. 1-52). San Diego, CA: Elsevier Academic Press.

Dovidio, J. F., Gluszek, A., John, M., Ditlmann, R. K., \& Lagunes, P. (2010). Understanding bias toward Latinos: Discrimination, dimensions of difference and experience of exclusion. Journal of Social Issues, 66(1), 59-78. doi:10.1111/ j.1540-4560.2009.01633.x

Dovidio, J. F., Kawakami, K., \& Gaertner, S. L. (2002). Implicit and explicit prejudice and interracial interaction. Journal of Personality and Social Psychology, 82(1), 62-68. doi:10.1037/0022-3514.82.1.62

Dutton, D. G. (1971). Reactions of restaurateurs to Blacks and Whites violating restaurant dress requirements. Canadian Journal of Behavioural Science/Revue Canadienne Des Sciences Du Comportement, 3(3), 298-302. doi:10.1037/ h0082272

Eagly, A. H., \& Karau, S. J. (2002). Role congruity theory of prejudice toward female leaders. Psychological Review, 109(3), 573-598. doi:10.1037/0033-295X.109.3.573

Ekman, P., \& Friesen, W. V. P. (1976). Pictures of facial affect. Palo Alto, CA: Consulting Psychologists Press.

Gerber, A., \& Green, D. (2012). Field experiments: Design, analysis and interpretation. New York: W.W. Norton.

Gutiérrez, A. S., \& Unzueta, M. M. (2010). The effect of interethnic ideologies on the likability of stereotypic vs. counterstereotypic minority targets. Journal of Experimental Social Psychology, 46(5), 775-784. doi:10.1016/j.jesp. 2010.03.010

Heckman, J. (1998). Detecting discrimination. Journal of Economic Perspectives, 12(2), 101-116.

Kahneman, D. (2011). Thinking, fast and slow. New York: Farrar, Straus and Giroux.

Kenney, G. M., \& Wissoker, D. A. (1994). An analysis of the correlates of discrimination facing young Hispanic job-seekers. The American Economic Review, 84(3), 674-683.

King, E. B., Shapiro, J. R., Hebl, M. R., Singletary, S. L., \& Turner, S. (2006). The stigma of obesity in customer service: A mechanism for remediation and bottom-line consequences of interpersonal discrimination. Journal of Applied Psychology, 91(3), 579-593. doi:10.1037/0021-9010.91.3.579

Lagunes, P., Levin, B., \& Ditlmann, R. (2012). Documenting the undocumented: A review of the United States' first municipal ID program. Harvard Journal of Hispanic Policy, 24, 43-62.

Lee, C. (2007). Hispanics and the death penalty: Discriminatory charging practices in San Joaquin county, California. Journal of Criminal Justice, 35(1), 17-27. doi:10.1016/j.jcrimjus.2006.11.012

Lyman, R. (2006, 15 August). Census shows growth of immigrants. The New York Times. Retrieved from http://www. nytimes.com/2006/08/15/us/15census.html?sq=immigrant \&st=nyt\&scp=1\&pagewanted=print

Manski, C. F. (1989). Schooling as experimentation: a reappraisal of the postsecondary dropout phenomenon. Economics of Education Review, 8(4), 305-312.

Marianne, P. (1995). Racial and ethnic discrimination in urban housing market: Evidence from a recent audit study. Journal of Urban Economics, 38(2), 183-306.

Marshall, S. R., \& Eberhardt, J. L. (2011). The function of animal associations: Latinos as rats and anti-immigrant sentiments. Poster presented at the annual Convention of the Society for Personality and Social Psychology, San Antonio, TX.

Massey, D. S., \& Sanchez, M. (2010). Brokered boundaries: Creating immigrant identity in anti-immigrant times. New York: Russell Sage Foundation.

MORI Research \& Newspaper Association of America. (2009). How America shops and spends 2009. Retrieved 22 December 2011 from http://www.naa.org/docs/NewspaperMedia/data/HowAmericaShopsandSpends.pdf

Ondrich, J., Stricker, A., \& Yinger, J. (1999). Do landlords discriminate? The incidence and causes of racial discrimination in rental housing markets. Journal of Housing Economics, 8(3), 185-204. doi:10.1006/jhec.1999.0249

Pager, D., Western, B., \& Bonikowski, B. (2009). Discrimination in a low-wage labor market: A field experiment. American Sociological Review, 74(5), 777-799. doi:10.1177/000312240907400505

Paluck, E. L. (2009). Reducing intergroup prejudice and conflict using the media: A field experiment in Rwanda. Journal of Personality and Social Psychology, 96(3), 574-587. doi:10.1037/a0011989 
Paluck, E. L., \& Green, D. (2009). Prejudice reduction: What works? A review and assessment of research and practice. Annual Review of Psychology, 60, 339-367. doi:10.1146/annurev.psych.60.110707.163607

Passel, J. S., \& Cohn, D. (2011). Unauthorized immigrant population: National and state trends, 2011. Retrieved on 25 December 2011 from http://pewhispanic.org/reports/report.php?ReportID=133

Pearson, A. R., Dovidio, J. F., \& Gaertner, S. L. (2009). The nature of contemporary prejudice: Insights from aversive racism. Social and Personality Psychology Compass, 3, 314-338. doi:10.1111/j.1751-9004.2009.00183.x

Pérez, D. J., Fortuna, L., \& Alegría, M. (2008). Prevalence and correlates of everyday discrimination among U.S. Latinos. Journal of Community Psychology, 36(4), 421-433. doi:10.1002/jcop.20221

Pew Research Center (2010). Blacks upbeat about Black progress, prospects: A year after Obama's election. Retrieved on 4 March 2011 from http://pewsocialtrends.org/2010/01/12/blacks-upbeat-about-black-progress-prospects/

Purdie-Vaughns, V., Steele, C. M., Davies, P. G., Ditlmann, R., \& Crosby, J. R. (2008). Social identity contingencies: How diversity cues signal threat or safety for African Americans in mainstream institutions. Journal of Personality and Social Psychology, 94(4), 615-630. doi:10.1037/0022-3514.94.4.615

Ramirez Berg, C. (2002). Latino images in film: Stereotypes, subversion, \& resistance. Austin: University of Texas Press.

Sadler, M. S., Correll, J, Park, B., \& M. Judd, C. M. (2012). The world is not black and white: Racial bias in the decision to shoot in a multiethnic context. Journal of Social Issues, 68(2), 286-313.

State of Arizona House of Representatives (2010, April 30). House Bill 2162. Retrieved 4 March 2011 from http:// www.azleg.gov/legtext/49leg/2r/bills/hb2162c.pdf

Sue, D. W., Capodilupo, C. M., Torino, G. C., Bucceri, J. M., Holder, A. M. B., Nadal, K. L., \& Esquilin, M. (2007). Racial micro-aggressions in everyday life: Implications for clinical practice. American Psychologist, 62(4), 271-286. doi:10.1037/0003-066X.62.4.271

Suro, R. (1998). Strangers among us: How Latino immigration is transforming America (1st ed.). New York: Alfred A. Knopf.

Vrij, A. (1993). Credibility judgments of detectives: The impact of nonverbal behavior, social skills and physical characteristics on impression formation. Journal of Social Psychology, 133(5), 601-610.

Weyant, J. M. (2005). Implicit stereotyping of Hispanics: Development and validity of a Hispanic version of the implicit association test. Hispanic Journal of Behavioral Sciences, 27(3), 355-363. doi:10.1177/0739986305276747

Zapana, V. (2008, 8 June). 1 year later ID card a mixed bag. The New Haven Register.

\section{Appendix A}
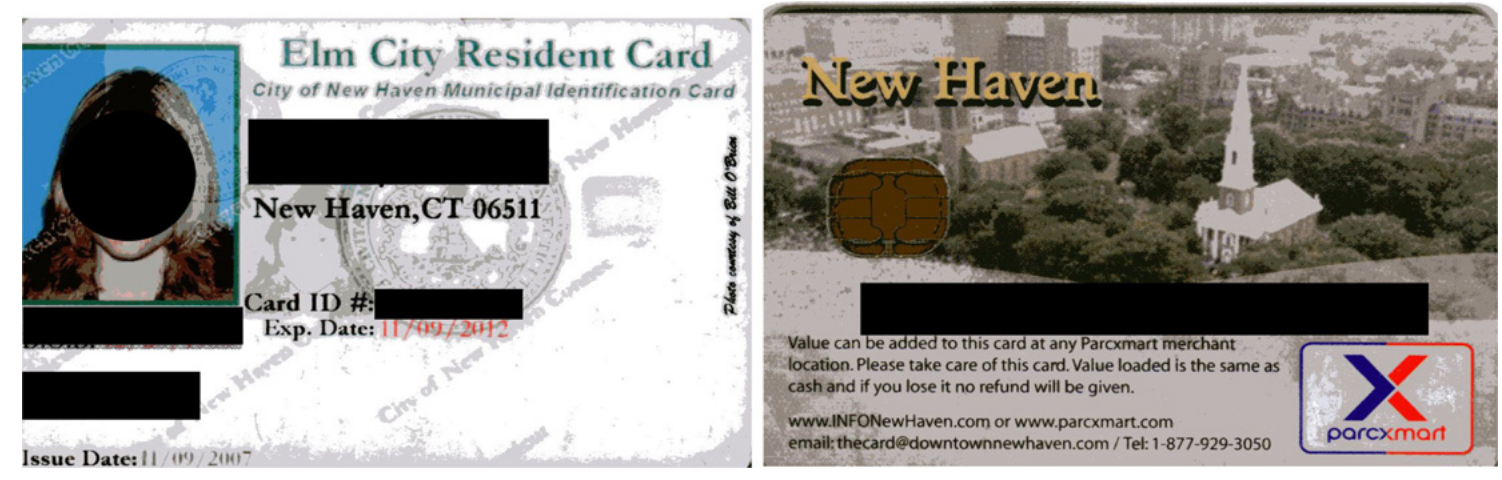

Figure AI. Municipal-issued card. 


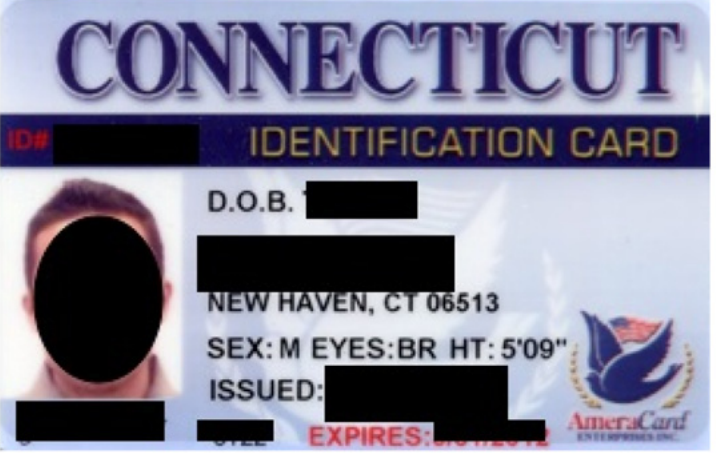

The holder of this card declares that the information provided on the face of this card is true and correct.

NOT AN OFFICIAL IDENTIFICATION CARD

Figure AII. Unofficial card.

\section{Appendix B}

In addition to the between group variability between Latino and White testers there was also a substantial amount of within group variability (see Table BI). However, even the lowest rate of ID request for a Latino tester was still higher than the highest rate for an Anglo tester.

Table BI. ID Request Rate for Individual Testers

\begin{tabular}{lccccccc}
\hline Individual Tester & \multicolumn{3}{c}{ Latino testers } & & \multicolumn{3}{c}{ Anglo testers } \\
\cline { 2 - 3 } & $\begin{array}{c}\text { Latino 1 } \\
(\mathrm{n}=41)\end{array}$ & $\begin{array}{c}\text { Latino 2 } \\
(\mathrm{n}=38)\end{array}$ & $\begin{array}{c}\text { Latino 3 } \\
(\mathrm{n}=32)\end{array}$ & & $\begin{array}{c}\text { White 1 } \\
(\mathrm{n}=44)\end{array}$ & $\begin{array}{c}\text { White 2 } \\
(\mathrm{n}=41)\end{array}$ & $\begin{array}{c}\text { White 3 } \\
(\mathrm{n}=21)\end{array}$ \\
\hline ID requested & 33 & 34 & 27 & & 30 & 32 & 16 \\
& $(81 \%)$ & $(90 \%)$ & $(84 \%)$ & & $(68 \%)$ & $(78 \%)$ & $(76 \%)$ \\
\hline
\end{tabular}

\section{Appendix C}

In our experiment the difference in how often salespersons declined the unofficial card from Latino versus Anglo testers was .24 percent points. Because they were not asked for ID, 5 Latino and 16 Anglo testers who were assigned to present the unofficial ID card dropped out before we observed the effect of the card (see Table I for the exact numbers). We determine the potential consequences of attrition by investigating how the estimated treatment effect varies depending on how we fill in missing potential outcomes (Manski, 1989; Gerber \& Green (2012)).

Table I. Means and Sample Sizes for All Four Groups in the Experiment Including Information about Attrition

\begin{tabular}{|c|c|c|c|c|}
\hline \multirow{2}{*}{$\frac{\# \text { of Stores }}{\text { Type of ID assigned }}$} & \multicolumn{2}{|c|}{ Latino testers $\left(\mathrm{n}=111^{\mathrm{a}}\right)$} & \multicolumn{2}{|c|}{ Anglo testers $\left(\mathrm{n}=106^{\mathrm{a}}\right)$} \\
\hline & $\begin{array}{c}\text { Municipal } \\
(\mathrm{n}=52)\end{array}$ & $\begin{array}{l}\text { Unofficial } \\
(\mathrm{n}=58)\end{array}$ & $\begin{array}{l}\text { Municipal } \\
(\mathrm{n}=45)\end{array}$ & $\begin{array}{c}\text { Unofficial } \\
(\mathrm{n}=60)\end{array}$ \\
\hline ID requested & 41 & 53 & 34 & 44 \\
\hline ID declined & 13 & 13 & 7 & 21 \\
\hline ID accepted & 28 & 40 & 27 & 23 \\
\hline
\end{tabular}

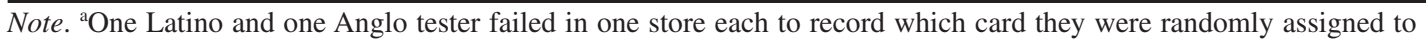
present. Thus, one case is missing and disregarded for each ethnicity. 
What might distinguish salespersons that did not request ID from those who did? Salespersons who did not request ID from Latinos and Anglos probably trust them to hold an official form of ID. The unofficial card violates that expectation and salespersons with high expectations would thus likely decline the card from both Latinos and Anglos. Assuming that all dropped out salespersons would have declined the unofficial card from both Latinos and Anglos yields the following treatment effect for tester ethnicity:

$$
[(.48 * .91)+(1 * .09)]-[(.24 * .73)+(1 * .27)]=.08
$$

Assuming that salespersons decline the unofficial card from all dropped out testers leads to a difference between Latinos and Anglos of .08. This effect is substantially smaller than .24 but still a positive difference favoring Latino testers.

Alternatively, salespersons who did not request ID might be more careless then others. Thus, they would likely accept the unofficial card from both Latinos and Anglos. Assuming that all dropped out salespersons would have accepted the unofficial card from both Latinos and Anglos yields the following treatment effect for tester ethnicity:

$$
[(.48 * .91)+(0 * .09)]-[(.24 * .73)+(0 * .27)]=.26
$$

Assuming that salespersons accept the unofficial card from all dropped out testers leads to a difference of .26. In the absence of an empirical test that circumvents attrition, for example, by always presenting ID regardless of whether it was requested, we rely on assumptions to estimate the exact size of the difference in decline of unofficial card from Latino versus Anglo testers. Obviously, this is far from ideal. However, we can at least conclude that the general biased treatment based on tester ethnicity effect holds up under the two main plausible assumptions about the salespersons that cause the attrition we contend with. 